STUDI

FRANCESI

\section{Studi Francesi}

Rivista quadrimestrale fondata da Franco Simone

172 (LVIII | I) | 2014

Varia

\title{
Rino Cortiana, Tra le pieghe dell'orizzonte. Parole e spazi nella poesia francese contemporanea
}

\section{Fabio Scotto}

\section{(2) OpenEdition}

1 Journals

\section{Edizione digitale}

URL: http://journals.openedition.org/studifrancesi/2287

DOI: 10.4000/studifrancesi.2287

ISSN: 2421-5856

\section{Editore}

Rosenberg \& Sellier

\section{Edizione cartacea}

Data di pubblicazione: 1 aprile 2014

Paginazione: 187-188

ISSN: 0039-2944

\section{Notizia bibliografica digitale}

Fabio Scotto, «Rino Cortiana, Tra le pieghe dell'orizzonte. Parole e spazi nella poesia francese

contemporanea », Studi Francesi [Online], 172 (LVIII | I) | 2014, online dal 01 avril 2014, consultato il 18 septembre 2020. URL : http://journals.openedition.org/studifrancesi/2287 ; DOI : https://doi.org/ 10.4000/studifrancesi.2287

Questo documento è stato generato automaticamente il 18 settembre 2020.

\section{(c) $(1) \odot$}

Studi Francesi è distribuita con Licenza Creative Commons Attribuzione - Non commerciale - Non opere derivate 4.0 Internazionale. 


\title{
Rino Cortiana, Tra le pieghe dell'orizzonte. Parole e spazi nella poesia francese contemporanea
}

\author{
Fabio Scotto
}

\section{NOTIZIA}

RINO CORTIANA, Tra le pieghe dell'orizzonte. Parole e spazi nella poesia francese contemporanea, Venezia, Marsilio, 2012 («Saggi»), pp. 204.

1 Con questo volume, Rino Cortiana, specialista di poesia francese contemporanea, in particolare di Blaise Cendrars, si prefigge di esplorare una nozione, quella di orizzonte e di spazialità che ha nel pensiero di Husserl (Meditazioni cartesiane) e di Merleau-Ponty il suo fondante substrato teorico-filosofico. Indagare, come spiega nella «Nota» d'apertura (pp. 7-8), il nesso fra geometrizzazione dello spazio e geometrizzazione della scrittura significa anche soffermarsi sulle dinamiche della percezione e dello sguardo, ovvero su quello che Michel Collot, cui si deve la più acuta e durevole esplorazione di queste problematiche nel tempo odierno, identifica come lo spazio esterno e interno al corpo. Nel capitolo liminare («L'orizzonte e i suoi nomi nella poesia francese contemporanea», pp. 9-21), Cortiana si sofferma su alcune esperienze maggiori della contemporaneità poetica, da Char a Jaccottet, da Bonnefoy a du Bouchet, al fine di mostrare in esse occorrimenti di toponimi (porta, muro, parete in Jaccottet), di figure geometriche (il cerchio in Bonnefoy), l'iteratività della linea d'orizzonte (l'espacement della pagina in du Bouchet), o in Char l'aforistica che lo delimita, secondo l'idea husserliana di «orizzonti come potenzialità delineate».

2 Muovendo da queste premesse teoriche fondamentali, l'A. studia poi la «geopoetica urbana» di Westwego di Soupault («Il vento dell'ovest: Westwego di Philippe Soupault», pp. 23-40), che pertinentemente ricollega alle esperienze d'esplorazione-erranza dell'universo cittadino e periferico di Apollinaire e Cendrars, o Reverdy. La «struttura 
deambulatoria» è qui associata a un movimento di caduta che include le classi sociali più umili ed emarginate, pur non limitandosi ad esse, ciò ricorrendo anche a immagini surrealiste della città letteraria, ritenuta un'amante dei poeti. In «Una meteora tra la costellazione e l'ambra: percorso di Orione nella poesia di René Char» (pp. 41-58) sono studiate le valenze mitologiche della figura di Orione in Aromates chasseurs, anche alla luce dell'esperienza pittorica di Poussin, autore di Paesaggio con Diana e Orione. Il viaggio di Orione verso la terra attraversa lo spazio celeste, in un allegorico percorso amoroso che rievoca tematiche della preziosità secentesca, fino all'approdo alla dimensione umana, luogo del disforico nel quale Orione e il poeta tendono a sovrapporsi, attraverso un percorso che dalla violenza e dalle immagini venatorie approda a esiti disseminatori pacificanti affini all'idea di martirio evocata da Derrida. La figura di Orione ritorna anche nel capitolo dedicato a du Bouchet («Il passo di Orione: lo spazio 'in avanti' nella poesia di André du Bouchet», pp. 99-125), mentre è studiato l'ethos jaccottetiano dello sguardo all'indietro memoriale che nel paesaggio interiore salvaguarda l'oggetto pur facendolo attraversare da una sorta di oblio mediante l'effacement («Il paesaggio e la memoria nella poesia di Philippe Jaccottet», pp. 59-72). Affine a questa ricerca la riflessione su Bonnefoy («I quadri nel paesaggio. Bonnefoy: L'Entroterra e i suoi incroci», pp. 163-181), che situa l'elaborazione espressiva all'intersezione fra il visivo e il verbale ancorandola alla suggestione dell'arte, nella dialettica fra il qui e l'altrove, fra l'immagine e il «vero luogo» che la trascende nell'immanenza. Vincolata alla dinamica dello sguardo e alla sua relazione con il tatto e l'udito, la sensorialità percettiva di Jean Tardieu lega la visione a un meccanismo di presentificazione e astrazione che rende il dato visivo prossimo alla funzione precipua di un oggetto geometrico utile a scandagliare il visibile o a rivelarne l'invisibile ( Visibile e non visibile nella poesia di Jean Tardieu», pp. 73-97), quando invece in Bernard Noël («Strategie espressive in Bernard Noël», pp. 183-204), l'anatomizzazione corporea crea di per sé uno spazio immaginario poeticamente esperibile attraverso una sorta di «auto-violenza» che ha come orizzonte la pelle, frontiera fra l'esterno e l'interno qui letta anche alla luce della nozione di «escrizione» di Jean-Luc Nancy, e come appendice fisico-espressiva della lingua, nel solco di Bataille e, per Cortiana, soprattutto di Mallarmé. Completano lo stimolante assieme due studi su Temple («Alberi e radici nella poesia di Frédéric Jacques Temple», pp. 143-161) e di Réda («'Corrispondenze e coincidenze’ nel viaggio poetico di Réda», pp. 127-141). 